\title{
Currículos socioemocionais, habilidades do século XXI e o investimento econômico na educação: as novas políticas curriculares em exame
}

\section{Socioemotional curricula, $21^{\text {st }}$ century skills and economic investment in education: the new curriculum policies under review}

\author{
Rodrigo Saballa de Carvalho ${ }^{1}$ \\ Roberto Rafael Dias da Silva ${ }^{2}$
}

\begin{abstract}
RESUMO
Nos regimes de implementação das políticas curriculares contemporâneas, noções como competências socioemocionais, habilidades do século XXI, paradigma holístico, currículo socioemocional e abordagem transversal tornaram-se recorrentes nos debates educacionais mobilizados pelos diferentes sistemas de ensino. O presente artigo é decorrente de uma pesquisa que, a partir do campo de Estudos das Políticas de Currículo, tem como objetivo problematizar a difusão de um modelo contemporâneo de currículo socioemocional que toma os estudantes como capital humano a ser investido. Para tanto, definiu-se como corpus de análise do artigo um modelo de currículo socioemocional colocado em ação no Rio de Janeiro, no qual são examinados: a) as racionalidades governamentais que operam na implementação do currículo; b) os sentidos de conhecimento escolar e formação humana engendrados na trama discursiva curricular. O artigo apresenta, então, um diagnóstico das articulações entre infância, escolarização e neoliberalismo.
\end{abstract}

\section{DOI: $10.1590 / 0104-4060.44451$}

1 Universidade Federal do Rio Grande do Sul. Porto Alegre, Rio Grande do Sul, Brasil. Programa de Pós-Graduação em Educação. Avenida Paulo Gama Farroupilha. CEP: 90040-060. E-mail: rsaballa@terra.com.br

2 Universidade do Vale do Rio dos Sinos. São Leopoldo, Rio Grande do Sul, Brasil. Programa de Pós-Graduação em Educação. Avenida Unisinos Cristo Rei. CEP: 93022-000. E-mail: robertoddsilva@yahoo.com.br 
A seguir, discute alguns desdobramentos subjetivos da teorização contemporânea nomeada como Big Five, analisando a promoção de um modelo de currículo socioemocional colocado em ação no Rio de Janeiro. Por fim, a partir das análises, infere que a indústria educacional contemporânea, motivada pelo imperativo de investimento econômico em educação, tem planejado tecnologias que operam no mapeamento e na tentativa de potencialização das competências socioemocionais dos alunos, tendo em vista sua qualificação enquanto capital humano.

Palavras-chave: políticas curriculares; currículos socioemocionais; competências socioemocionais; capital humano.

\begin{abstract}
In the implementation programs of contemporary curriculum policies, concepts such as socioemotional skills, $21^{\text {st }}$ century abilities, holistic paradigm, socioemotional curriculum and transversal approach have become recurrent in educational debates mobilized by different education systems. This article results from a research that, from the field of Studies on Curriculum Policies, aims to discuss the diffusion of a contemporary model of socioemotional curriculum that takes students as human capital in which to invest. To this end, for the article, it was defined as an analytical corpus the socioemotional curriculum model put into action in Rio de Janeiro, in which are examined: a) government rationality operating in the implementation of the curriculum; b) the senses of school knowledge and human development engendered in the curriculum discourse network. The article then presents a diagnosis of links between childhood, school education and neoliberalism. After that, it discusses some subjective unfolding of the contemporary theorization named Big Five, analyzing the promotion of a socioemotional curriculum model put into action in Rio de Janeiro. Finally, from the analyses, it infers that the contemporary educational industry, driven by the imperative of economic investment in education, has planned technologies operating in mapping and trying to enhance socioemotional skills of students, aiming at their qualification as human capital.
\end{abstract}

Keywords: curriculum policies; socioemotional curricula; socioemotional skills; human capital.

Uma revista informativa brasileira, no mês de abril de 2015, apresentou uma entrevista com James Heckman, Prêmio Nobel de Economia no ano de 2001. Entretanto, diferentemente do que se possa imaginar, as páginas jornalísticas não traziam elementos vinculados à área estritamente econômica, mas ampliavam seu campo de intervenção para pensar a educação das crianças de 
nosso País. Heckman (2015) ${ }^{3}$, na referida entrevista, assumia como um de seus posicionamentos que "tentar sedimentar num adolescente o conhecimento que deveria ter sido apresentado a ele dez anos antes custa mais e é menos eficiente". Mais que evidenciar um conjunto de pressupostos para pensar as políticas de escolarização, a partir do engendramento de uma matriz econômica, a entrevista com o professor da Universidade de Chicago enuncia uma racionalidade política contemporânea que posiciona a educação escolar como objeto de intervenção governamental, equacionada enquanto um investimento econômico.

Todavia, o referido texto não é uma elaboração ocasional. Em uma significativa trama governamental, são inúmeros os institutos, organizações não governamentais, agências multilaterais, atores políticos e grupos educacionais que operam na difusão desses princípios. (SHORE; WRIGHT, 1997; PENN, 2002; BALL, 2014). Evidencia-se, em nosso tempo, uma difusão de modelos de currículos socioemocionais que tomam a infância como alvo privilegiado para o investimento econômico. Mais uma vez recorrendo a Heckman (2015), as próprias famílias passam a ser reposicionadas no interior dessa lógica política. Em suas palavras, "elas indicam que qualquer tipo de intervenção que consiga despertar o interesse dos pais e fazê-los estimular, desde cedo, o aprendizado cognitivo e emocional dos filhos tem excelente custo-benefício". Pensar a escolarização em termos de investimentos econômicos sobre a vida nos inquieta, do ponto de vista investigativo.

Ao colocarmos em exame os regimes de implementação das políticas curriculares em curso em determinadas regiões de nosso país, imediatamente encontraremos a proliferação de uma nova gramática formativa. (NASCIMENTO, 2013). Noções como competências socioemocionais, habilidades do século XXI, paradigma holístico, currículo socioemocional e abordagem transversal tornaram-se recorrentes nos debates educacionais mobilizados pelos diferentes sistemas de ensino, especialmente no período em que estivemos envolvidos nas questões atinentes à base nacional comum curricular. Que racionalidades governamentais operam na implementação dessas políticas de currículo? Quais sentidos de conhecimento escolar e formação humana são engendrados no interior dessa trama discursiva? Como as propostas curriculares são ressignificadas no contexto das competências socioemocionais?

Com essas interrogações, organizamos o presente artigo em três seções. Na primeira, produzimos um breve diagnóstico das possíveis articulações entre

3 James J. Heckman é professor de Economia da Universidade de Chicago e professor de Ciências e Sociedade da Universidade de Dublin. É pesquisador da área de Economia da Educação Infantil e possui a Fundação Heckman Equation, que busca disseminar os valores do investimento em Educação Infantil. 
infância, escolarização e neoliberalismo, valendo-nos de uma abordagem pluralista para o estudo das políticas educacionais. (TELLO; MAINARDES, 2015). A seguir, na segunda seção, exploramos alguns desdobramentos subjetivos da teorização contemporânea nomeada como Big Five, inspiradora das atuais reformas com ênfase nas competências socioemocionais. Por fim, a partir da implementação de uma experiência colocada em ação no Rio de Janeiro, analisamos a promoção de currículos socioemocionais centrados nas competências no século XXI.

\section{Infância, escolarização e neoliberalismo: um diagnóstico}

Pesquisas internacionais de longo prazo sobre programas de educação para crianças pobres insistem em evidenciar que intervenções precoces são eficientes, porque aumentam significativamente os resultados em avaliações de larga escala e a probabilidade de que o estudante complete o ciclo educacional básico. Além disso, tais programas são apontados como promotores da redução da retenção escolar, do tempo de permanência dos estudantes em classes especiais, da criminalidade, das taxas de natalidade e da delinquência entre os jovens. (CUNHA et al., 2005). Pesquisadores como James Heckman. (CUNHA; HECKMAN, 2011; HECKMAN, 2006, 2008), anteriormente referido, defendem a eficiência econômica da Educação Infantil e a importância de programas de educação da primeira infância como solução dos diversos problemas de ordem econômica, política e social que afetam os países em desenvolvimento. Desse modo, a inclusão da população infantil de baixa renda em programas de educação, conforme Fumagalli (2010), visa assegurar as condições básicas de sobrevivência dos indivíduos e, ao mesmo tempo, incluí-los no jogo do mercado, gerenciando e minimizando os riscos que aqueles cobertos por tais políticas representam para si mesmos, para os outros e para o Estado.

De acordo com Penn (2002), os preceitos de interpretação e de práticas modeladas para crianças nos Estados Unidos são divulgados de forma indiscriminada como perfeitamente legítimos para o mundo majoritário (subdesenvolvido do Sul, do Terceiro Mundo). Para a referida autora, os pesquisadores alegam que a única evidência e experiência válida provém dos Estados Unidos, pois defendem a ideia de que ninguém mais testou os pressupostos relativos à primeira infância com a mesma intensidade que eles - desconsiderando que outros países possam não considerar válida ou necessária a operacionalização de programas de intervenção precoce para justificar gastos com crianças pequenas. Fundamentada na confluência dos estudos da neurociência e da economia que 
tomam como parâmetro um modelo universal de desenvolvimento humano, os argumentos apresentados nos estudos dos economistas estão disseminando-se através dos documentos produzidos pelo Banco Mundial e tornando-se referência para o planejamento e a operacionalização de políticas de Educação Infantil em diversos países. Todavia, conforme Moss (2011), o que chama a atenção é o fato de que, nos Estados Unidos, país no qual emergiram os estudos de intervenção precoce $^{4}$, na década de 1960 , as taxas de pobreza entre as crianças estavam $22 \%$ mais altas em 2010 do que em 1965, quando se iniciaram os programas citados pelos pesquisadores.

Nas análises econômicas, de acordo com Esping-Andersen (2007), a infância que está à margem das condições de vida consideradas produtivas pelo Estado neoliberal é considerada um risco social que demanda intervenção, acompanhamento e avaliação. Por esse motivo, as crianças oriundas de famílias de baixa renda têm sido vistas como capital humano a ser desenvolvido em termos de conhecimentos específicos, habilidades e destrezas.

Corroborando o argumento, Nascimento (2013) destaca que os analistas econômicos têm defendido o investimento em Educação Infantil como promotor de vantagens para as classes de baixa renda, devido à ampliação do tempo que as famílias têm, enquanto os filhos estão na escola, para se dedicarem ao trabalho e gerarem renda. Desse modo, é possível observar, por meio das políticas de escolarização contemporâneas, que os investimentos em capital humano infantil estão se efetivando predominantemente por meio da educação da criança desde a mais tenra idade, tendo em vista a preparação de indivíduos capacitados para uma atividade laboral futura. (LUPTON, 1999).

$\mathrm{O}$ argumento central utilizado de modo recorrente pelos pesquisadores é que uma educação de qualidade possibilita a formação de pessoas mais eficientes economicamente, pois tem efeitos diretos sobre fatores socioeconômicos, como o aumento de emprego, renda e escolaridade e a redução de riscos, como o número de gestações indesejadas, de atitudes violentas, dentre outros aspectos que trazem prejuízos ao desenvolvimento dos países. As contribuições decorrentes do investimento educacional realizado, conforme Heckman $(2006,2008)$ e Cunha e Heckman (2011), aumentam indefectivelmente a renda nacional, a redução dos níveis de pobreza e a menor necessidade de programas sociais compensatórios.

Desse modo, a partir de uma formalização cada vez maior das políticas para a educação no Brasil, em 2001 foi aprovado o primeiro Plano Nacional de Educação (PNE), para o período de 2001 a 2010, previsto na Constituição Federal. (BRASIL, 1988). O primeiro PNE previu a ampliação do atendimento

4 Head Start, Perry Preschool Program, High Scope, Chicago Child-Parent Centers (CPC), Abecedarian Program, dentre outros programas. 
da Educação Infantil e a extensão da escolaridade obrigatória para crianças de 6 anos de idade. Em 2006, as crianças de 6 anos de idade foram transferidas da Educação Infantil para o Ensino Fundamental, uma vez que a Lei n ${ }^{\circ} 11.114$, de 16 de maio de 2005, instituiu o início da obrigatoriedade do Ensino Fundamental aos 6 anos. A ampliação do Ensino Fundamental de oito para nove anos de duração, de acordo com Correa (2011), ocasionou mudanças no currículo da pré-escola e, em muitos casos, uma intensificação precoce do processo de escolarização das crianças na Educação Infantil.

Argumentando na mesma linha analítica, Moss (2011) destaca que o modelo de prontidão para a escola está implicado em uma lógica que define a educação das crianças como estratégia de retorno econômico. Conforme o autor, tal modelo não é recente, mas tem acentuado os argumentos de pesquisadores da área da economia sobre a importância do investimento na pequena infância. Isso porque o saber decorrente da expertise econômica possibilita adotar, no campo da intervenção governamental, técnicas e estratégias que objetivam governar os homens e as coisas. (FOUCAULT, 2008).

Além disso, no que diz respeito à preocupação com a preparação das crianças para o Ensino Fundamental e, de modo correlato, para as avaliações em larga escala (Provinha Brasil, Prova Brasil, dentre outros) comumente utilizadas em nosso país, temos também evidenciado a contratação de sistemas privados de ensino por redes educacionais públicas e a adoção de apostilas para o trabalho pedagógico das diferentes etapas da Educação Básica. Esse trabalho pedagógico apostilado, segundo Nascimento (2012), não atende às proposições das Diretrizes Curriculares Nacionais, caracterizando-se fundamentalmente como "curso preparatório" para as etapas posteriores da escolarização.

A Emenda Constitucional ${ }^{\circ}$ 59, de 11 de novembro de 2009, tornou obrigatória a matrícula de crianças de 4 e 5 anos, o que também foi modificado na Lei de Diretrizes e Bases da Educação pela Lei no 12.796, de 4 de abril de 2013. Nesse sentido, a Emenda Constitucional aponta para uma ruptura da Educação Infantil entre 0 e 3 anos e 4 e 5 anos, o que causa um impacto negativo na oferta de atendimento às crianças menores. Conforme Rosemberg (2010), o atendimento de 0 a 3 anos no Brasil é muito deficitário, e, com a emenda, corre-se o risco de que esse déficit seja ampliado através de conveniamentos, terceirizações e incentivo ao desenvolvimento de programas de ação familiar. Outro ponto de grande impacto a ser considerado é a probabilidade de escolarização precoce das crianças de 4 e 5 anos, a partir do aumento do número de crianças por sala de aula para garantir o atendimento e a antecipação do currículo desenvolvido no Ensino Fundamental.

Reafirmando a obrigatoriedade da Educação Infantil a partir dos 4 anos de idade, o novo PNE (2011-2020), em sua primeira meta, apresenta o propósito 
de universalização do ensino escolar da população de 4 e 5 anos até 2016 e a ampliação do atendimento das crianças de até 3 anos, de forma a cobrir 50\% dessa população. Além disso, vale mencionar que o novo PNE apresenta como uma das estratégias da Meta 1 " [...] avaliar a Educação Infantil com base em instrumentos nacionais, a fim de aferir a infraestrutura física, o quadro de pessoal e os recursos pedagógicos e de acessibilidade empregados na creche e na pré-escola". (CORREA, 2011, p. 107).

Tal estratégia, de acordo com Nascimento (2013), gerou várias controvérsias, pois serviu de justificativa para a Secretaria de Assuntos Estratégicos (SAE), órgão diretamente vinculado à Presidência da República, aplicar uma avaliação de larga escala (ASQ-3) na cidade do Rio de Janeiro, tendo em vista a aferição do desenvolvimento das crianças e a qualidade dos serviços prestados por instituições públicas de Educação Infantil $1^{5}$.

Esse instrumento tomou como padrão normativo de excelência de desenvolvimento a classe média branca estadunidense. Os resultados da avaliação realizada apontaram que $26 \%$ das crianças cariocas submetidas aos testes se encontram em desvantagem em relação aos seus pares estadunidenses. No site da SAE, ainda, foi apresentado um ranking das creches que obtiveram os "melhores" resultados em termos de desenvolvimento das crianças.

Sem dúvida alguma, tratou-se de uma interpretação economicista da educação, baseada em parâmetros produzidos no contexto estadunidense do que seja uma Educação Infantil de qualidade, a qual, devido à crítica dos pesquisadores do campo da Educação Infantil no Brasil, não foi levada adiante enquanto política de avaliação das crianças. Esses parâmetros são criticados por Penn (2002) e Moss (2011) quando afirmam que os Estados Unidos dispõem de um dos mais desiguais e injustos sistemas de Educação Infantil do mundo. Corroborando o argumento apresentado, Shore e Wright (1997) indicam, por meio de suas pesquisas, quais pressupostos e práticas neoliberais estão sendo reportados para os países em desenvolvimento, a partir da implantação de modos particulares de governar. As autoras destacam ainda que, frente à existência dos problemas sociais contemporâneos, as políticas introduzem formas particulares de definir e de solucionar os problemas sociais. Do ponto de vista dos investimentos subjetivos, como evidenciaremos na próxima seção, constatamos uma ênfase nas teorizações nomeadas como Big Five.

5 O ASQ-3 teve a sua pesquisa realizada no Rio de Janeiro. Devido a um conjunto de críticas, esse tipo de avaliação não se efetivou enquanto política educacional. O SENNA (Avaliação das Competências Socioemocionais), examinado na Seção 3, não focaliza a Educação Infantil, mas é uma nova tentativa de implantação de um programa cuja base são os valores econômicos. Em nossa hipótese, muda-se o foco, visto que são enfatizados os anos finais do Ensino Fundamental e o Ensino Médio; todavia, intensifica-se a lógica econômica. 


\section{Big Five: novos investimentos subjetivos}

Do ponto de vista da fabricação das subjetividades contemporâneas, para ampliar as formas de abordagem das racionalidades governamentais que, em nossa perspectiva, operam em rede e das possibilidades de capitalização de vida através da inovação, importa trazer as contribuições de Miller e Rose (2012). Seria conveniente pensarmos nos modos pelos quais as questões da inscrição e do cálculo se tornam tecnologias de governo.

Com a emergência da estatística, no decorrer do século XVIII, passamos a representar de diferentes formas os objetos a serem governados. A estatística foi considerada o conhecimento das forças e dos recursos que caracterizavam o Estado, como, por exemplo, conhecimento da população (número de indivíduos, de mortos, de nascidos), estimativa da riqueza dos indivíduos, das diferentes categorias de indivíduos, das riquezas que o Estado possuía, entre outros aspectos que passaram a ser o conteúdo essencial do saber do soberano. (SENRA, 2005). As questões relativas à saúde, à longevidade, à educação e à capacidade produtiva da população, enquanto coletivo a ser administrado, passaram a ser uma preocupação do Estado. A partir de então, o Estado passou a focar sua atenção na população, através da definição de objetivos a serem alcançados e da proposição de ações que visavam potencializar as ações produtivas, identificando os problemas e minimizando-os por intervenções que buscavam a organização dos indivíduos de modo mais eficaz (LUPTON, 1999). A primeira estratégia vinculou-se à elaboração de "dispositivos de inscrição". (MILLER; ROSE, 2012, p. 84). Mediante a operacionalização desses dispositivos, as informações sobre a população passaram a ser traduzidas em debates e diagnósticos, tornando as realidades comparáveis.

Miller e Rose (2012, p. 85) assinalam que as formas de inscrição da realidade passaram a se constituir como "centros de cálculo". Isso porque as informações inscritas em determinadas racionalidades governamentais adquirem intensa potencialidade quando calculadas. No caso deste artigo, esse sentido político atribuído à inscrição e ao cálculo possibilita pensar como uma racionalidade específica do nosso tempo - o investimento no desenvolvimento de competências socioemocionais - organiza determinadas formas de conduzir as condutas dos sujeitos e das populações, possibilitando o planejamento de estratégias relativas à gestão de fatores de risco que podem ser desencadeados pela falta de investimento em tal campo. Essas estratégias, conforme apresentaremos posteriormente, são planejadas sob a justificativa de que o risco social de "produzir" cidadãos que não tenham competências socioemocionais desen- 
volvidas, além de gerar altos custos para o país, torna uma parcela da população dependente da tutela do Estado para resolver seus problemas.

Como destacaremos nos documentos a serem analisados, a educação é significada nas análises dos experts do campo da economia como um espaço de intervenção que deve ser conhecido e administrado por meio de programas governamentais, como é o caso da proposição de currículos socioemocionais. Isso porque é o caráter calculável da população que passa pela escola que enseja a possibilidade de intervenções cada vez mais precisas, dirigidas à miríade de problemas que afetam a vida das crianças e jovens. Isso ocorre, conforme O’Malley (1996), Lupton (1999) e Bujes (2010), porque a noção de risco e as práticas dela derivadas estão associadas à sociedade de segurança, a qual permite inserir determinados fenômenos dentro de uma série de acontecimentos prováveis.

Pode-se depreender, então, que os dispositivos de inscrição se tornaram o terreno comum das formas contemporâneas de racionalidade política, orientando, de acordo com Foucault (2008), Miller e Rose (2012), as tarefas dos governantes em termos de supervisão e maximização calculada das forças da sociedade a partir do processo de escolarização de crianças e jovens. Além disso, é evidente o imperativo de que sejam inventados indivíduos, desde a infância, com mais habilidades e flexibilidade para mudanças, de forma que possam se tornar adultos produtivos, participantes do jogo do consumo e empreendedores de si mesmos. (LÓPEZ-RUIZ, 2007; GADELHA, 2009).

A partir do argumento apresentado, é evidente que a população escolar pobre se torna o centro das ações de governo, implicando investimentos que buscam priorizar esforços em direção a racionalidades de governamento da conduta das crianças e das pessoas envolvidas com sua educação. Nessas bases, a tarefa do governo, prescrita pelos economistas, é estruturar estratégias que potencializem o desenvolvimento de competências socioemocionais em crianças e jovens, reduzindo riscos futuros. Para tanto, as análises dos economistas partem de pressupostos universais sobre o desenvolvimento socioemocional de crianças e jovens, construindo suas argumentações a partir de um modelo “padrão" definido pela expertise psicológica. (SMOLKA et al., 2015). É a partir desse modelo que são propostos programas curriculares baseados no Big Five, tendo em vista o desenvolvimento de competências socioemocionais.

As teorizações centradas nos modelos do Big Five apontam um conjunto de cinco grandes fatores que, enquanto traços de personalidade, podem ser medidos cientificamente, em especial em seu potencial para as organizações. De acordo com Fruyt (2014), em atividade desenvolvida pelo Instituto Ayrton Senna, a referida teorização apresenta significativos impactos para a escolarização contemporânea, sobretudo ao enfatizar questões como a amabilidade, a extroversão, 
a estabilidade emocional, a conscienciosidade e a abertura a mudanças. No limite, segundo o psicólogo, além de intensificar a busca por resultados educacionais futuros, a teoria do Big Five permite um ensino mais personalizado.

De fato, o Big Five é exatamente sobre isso. Ele proporciona uma descrição do indivíduo nas características que diferenciam uma criança/ jovem de seus pares e cria, então, a possibilidade de alinhar o ambiente de aprendizagem de acordo com a individualidade, proporcionando por isso um ensino melhor. Por exemplo, considerando dois alunos com diferenças no cruzamento entre Abertura e Conscienciosidade: Manuela é menos criativa, mas metódica e comprometida, enquanto Luis gosta de criar e experimentar coisas, mas tem dificuldade de se manter um planejamento. Ambos irão aprender de formas muito diferentes e os professores deverão oferecer um suporte diferente a cada um: o professor de Manuela terá que usar tempo extra para elaborar uma tarefa pré-estruturada de aprendizagem para ela, enquanto Luis vai preferir uma atividade mais aberta, mas que exigirá de seu professor um acompanhamento mais intenso sobre seu progresso. (FRUYT, 2014, p. 1).

Os investimentos econômicos na escolarização associados às emergentes demandas por personalização dos percursos formativos caracterizam as políticas curriculares examinadas neste artigo. Como podemos diferenciar os percursos formativos dos estudantes? Que possibilidades de intervenção subjetiva se derivam dessa grade de intervenção pedagógica? Quais sentidos de formação humana emergem dos investimentos econômicos mobilizados em tais políticas? Que resultados se fazem possíveis das avaliações de larga escala colocadas em ação em tais contextos? A seguir, exploraremos como exemplar analítico algumas estratégias mobilizadas na implementação do projeto Dupla Escola, no Estado do Rio de Janeiro. Entretanto, antes de situá-lo no interior de determinadas racionalidades políticas, assinalamos entendimentos provisórios sobre as formas interventivas mobilizadas por um Estado que opera em rede. (BALL, 2014).

\section{Currículos socioemocionais e competências no século XXI: um estudo curricular}

Como sinalizamos acima, para produzirmos uma análise das formas contemporâneas de organização dos Estados, em especial no que tange às políticas 
educacionais, uma das noções importantes é a de redes políticas, evidenciada nos estudos recentes de Ball (2014). De acordo com o sociólogo, redes políticas “[...] são um tipo de 'social' novo, envolvendo tipos específicos de relações sociais, de fluxos e de movimentos". (BALL, 2014, p. 29). A rede passa a funcionar como um operador analítico para a compreensão da tessitura política de nosso tempo, na qual agentes públicos e privados se entrelaçam na efetivação das intencionalidades compartilhadas para pensar as questões sociais e suas possíveis soluções. Em tais condições, um conjunto de novos atores políticos adquire centralidade no direcionamento dos discursos da política, seja por meio de novas articulações, seja através da validação de novos argumentos e comunidades produtoras de sentidos.

São variadas as formas de conexão e de relacionamento entre os integrantes dessas redes políticas. Na acepção do autor, "a política está sendo privatizada em vários sentidos”. (BALL, 2014, p. 32). Podemos depreender, então, que a noção de rede se torna relevante para descrevermos as novas formas de governança em ação. Todavia, cabe explicitar que "[...] as formas de governança em rede não são fixas e podem conter alguns componentes fugazes, frágeis e experimentais" (BALL, 2014, p. 33). Agências internacionais, governos locais, institutos diversos, consultores e "empreendedores de políticas" passam a mobilizar-se de forma "estruturalmente acopladas". (JESSOP, 2006).

Uma das decorrências analíticas dessas novas formas de governança diz respeito à emergência de variadas formas de mobilidade das políticas. Ou seja, empresas e agentes privados diversos, no âmbito da mobilidade, assumem protagonismo na difusão de novos pressupostos orientadores das políticas educacionais, em/para diferentes regiões do planeta. Em escala global, tais ações "[...] incluem novas formas de filantropia e de ajuda para o desenvolvimento educacional, para os processos de mercado de crescimento e expansão de capital e a busca por parte das empresas de novas oportunidades para lucro". (BALL, 2014, p. 37). Como derivação dessa atuação, dentre outras questões, poderíamos assinalar a fabricação de novas formas de "convergência". (BALL, 2014), desenvolvidas através de intensa atuação política dos novos atores integrantes da rede política, no âmbito local.

Examinando publicações recentes, engendradas no contexto de determinada rede política contemporânea, encontramos algumas conexões discursivas envolvendo a promoção de competências socioemocionais, educação para o século XXI e aprendizagens permanentes. Um desses documentos, publicado pelo Instituto Ayrton Senna, parte do pressuposto de que "[...] formar crianças e jovens para superar os desafios do século XXI requer o desenvolvimento de um conjunto de competências necessárias para aprender, viver, conviver e trabalhar em um mundo cada vez mais complexo". (IAS, 2014, p. 4). Em tais condições, constata-se uma crítica aos modelos curriculares mais convencionais, centrados 
em conhecimentos disciplinares, uma vez que, de acordo com os formuladores do documento, a sociedade espera jovens com outro perfil formativo. A solução de problemas de maneira colaborativa, o pensamento crítico e criativo e a capacidade de fazer escolhas responsáveis são algumas das demandas apresentadas para a escola do novo século.

Inspirado em paradigmas holísticos da educação, geralmente vinculados ao desenvolvimento humano, o documento analisado prioriza a educação como promotora de oportunidades, capaz de preparar indivíduos aptos a realizar escolhas e a transformar suas competências em potencial. (IAS, 2014). Para tanto, é proposta uma concepção de educação na qual

[...] a ênfase recai em aspectos socioemocionais que capacitam as pessoas para buscarem o que desejam, tomarem decisões, estabelecerem objetivos e persistirem no seu alcance mesmo em situações adversas, de modo a serem protagonistas do seu próprio desenvolvimento e de suas comunidades e países. (IAS, 2014, p. 5).

Em outras palavras, encaminha-se como forma mais eficaz para a escolarização do século XXI "[...] um investimento nos aspectos socioemocionais para alavancar a aprendizagem". (IAS, 2014, p. 6, grifo dos autores).

As competências propostas pelo Instituto Ayrton Senna são apresentadas como vetores para direcionar as inovações curriculares, sobretudo ao focalizarem aspectos cognitivos e socioemocionais. Responsabilidade, colaboração, comunicação, criatividade e autocontrole se tornam questões a serem priorizadas nas proposições curriculares, ao mesmo tempo que objetos de avaliação em larga escala. (IAS, 2014). Retomando o documento examinado, um breve vocabulário explicativo enuncia alguns desses pressupostos:

Competência: capacidade de mobilizar, articular e colocar em prática conhecimentos, valores, atitudes e habilidades, seja no aspecto cognitivo, seja no aspecto socioemocional, ou na inter-relação dos dois.

No aspecto da competência socioemocional: para se relacionar com os outros e consigo mesmo, compreender e gerir emoções, estabelecer e atingir objetivos, tomar decisões autônomas e responsáveis e enfrentar situações adversas de maneira criativa e construtiva. As competências socioemocionais priorizadas nesse contexto são aquelas que desempenham um papel crucial na obtenção do sucesso escolar e na vida futura das crianças e jovens. 
No aspecto da competência cognitiva: para interpretar, refletir, raciocinar, pensar abstratamente, assimilar ideias complexas, resolver problemas e generalizar aprendizados. (IAS, 2014, p. 9, grifos dos autores).

A partir desse conjunto de competências, assinala-se a importância da efetivação de políticas públicas e práticas pedagógicas sintonizadas com esses princípios. Implica-se também que, para a construção do século XXI, precisamos de currículos apropriados, formação de professores e o estabelecimento de padrões de inovação. (IAS, 2014).

Exemplar nessa direção é o projeto Solução Educacional para o Ensino Médio conduzido pelo Instituto Ayrton Senna, em parceria com a OCDE e a Secretaria Estadual de Educação do Rio de Janeiro. Esse projeto, alicerçado na inovação e na diferenciação dos currículos escolares,

[...] propõe-se ensinar os conteúdos curriculares a partir de uma matriz de competências para o século XXI, flexível e customizável a diferentes modelos de escola - que combina competências cognitivas - como a resolução de problemas e o pensamento crítico - com competências socioemocionais - como a colaboração e a responsabilidade. (IAS, 2014, p. 13).

Em torno do projeto Solução Educacional, para além da própria centralidade das competências socioemocionais, despertam nossa atenção as estratégias mobilizadas para sua avaliação em larga escala. A intenção explicitada nesse documento se vincula ao objetivo de "[...] ampliar o repertório de ferramentas de avaliação que compõem esses sistemas - e contribuir, portanto, para a ampliação das fronteiras do que se entende por educação de qualidade". (IAS, 2014, p. 22, grifos dos autores). A referida modalidade de avaliação de competências se mobiliza em duas dimensões, quais sejam, formativa e somativa (IAS, 2014), aproximando-as de questões socioeconômicas.

Para o acompanhamento desse processo, foi desenvolvido o sistema SENNA (Social and Emotional or Non-cognitive Nationwide Assessment). Tal sistema "[...] será disponibilizado para apoiar gestores e educadores na tarefa de formular, executar e reorientar políticas públicas e práticas pedagógicas destinadas a melhorar a qualidade da educação no Brasil". (IAS, 2014, p. 22). A matriz orientadora do sistema SENNA contém tanto as competências a serem adquiridas pelos indivíduos quanto as atitudes esperadas que os alunos desenvolvam em suas condutas cotidianas. Ou seja, a matriz orientadora pode ser 
considerada, em última instância, um tipo de tecnologia que busca programar e controlar os estudantes em sua forma de agir, sentir, pensar e situar-se diante de si mesmos, da vida que levam e do mundo em que vivem. (O'MALLEY, 1996; GADELHA, 2009). O Quadro 1 dá visibilidade para essa lógica organizativa.

\section{QUADRO 1 - MODELO DE CLASSIFICAÇÃO DAS COMPETÊNCIAS}

\begin{tabular}{|c|c|c|c|c|c|}
\hline Dimensão & $\begin{array}{l}\text { Estabelecimento e } \\
\text { alcance de objeti- } \\
\text { vos (Consciencio- } \\
\text { sidade) }\end{array}$ & $\begin{array}{l}\text { Respeito } r \\
\text { cuidado pelos } \\
\text { outros (Amabi- } \\
\text { lidade) }\end{array}$ & $\begin{array}{l}\text { Sociabilidade e } \\
\text { entusiasmo (Ex- } \\
\text { troversão) }\end{array}$ & $\begin{array}{l}\text { Abertura para } \\
\text { o novo (Aber- } \\
\text { tura) }\end{array}$ & $\begin{array}{l}\text { Gestão das } \\
\text { emoções } \\
\text { bilidade } \\
\text { cionta- } \\
\text { emo- }\end{array}$ \\
\hline Competência & $\begin{array}{l}\text { Ex.: Responsabili- } \\
\text { dade }\end{array}$ & $\begin{array}{l}\text { Ex.: Colabora- } \\
\text { ção }\end{array}$ & $\begin{array}{l}\text { Ex.: } \\
\text { cação }\end{array}$ & $\begin{array}{ll}\text { Ex.: } & \text { Curiosi- } \\
\text { dade } & \end{array}$ & $\begin{array}{l}\text { Ex.: Autocon- } \\
\text { trole }\end{array}$ \\
\hline Atitude & $\begin{array}{l}\text { Ex.: O aluno vai } \\
\text { preparado para as } \\
\text { aulas; permanece } \\
\text { comprometido com } \\
\text { seus objetivos mes- } \\
\text { mo que levem mui- } \\
\text { to tempo para serem } \\
\text { alcançados. }\end{array}$ & $\begin{array}{l}\text { Ex.: O aluno } \\
\text { encontra solu- } \\
\text { ções em meio } \\
\text { a conflito com } \\
\text { os colegas; de- } \\
\text { monstra respeito } \\
\text { pelo sentimento } \\
\text { dos outros. }\end{array}$ & $\begin{array}{l}\text { Ex.: O aluno } \\
\text { participa ativa- } \\
\text { mente; encara as } \\
\text { atividades com } \\
\text { entusiasmo. }\end{array}$ & $\begin{array}{l}\text { Ex.: O alu- } \\
\text { no demonstra } \\
\text { interesse em } \\
\text { aprender; faz } \\
\text { perguntas para } \\
\text { melhorar a } \\
\text { compreensão. }\end{array}$ & $\begin{array}{ll}\text { Ex.: O } & \text { aluno } \\
\text { permanece cal- } \\
\text { mo } & \text { mesmo } \\
\text { quando } & \text { critica- } \\
\text { do ou } & \text { provo- } \\
\text { cado. } & \end{array}$ \\
\hline
\end{tabular}

FONTE: IAS (2014).

O modelo de classificação das competências, acima evidenciado, é colocado em ação através de dois questionários preenchidos pelos estudantes e pelos professores. O Questionário Socioemocional é respondido pelos estudantes do $5^{\circ}$ ano do Ensino Fundamental ao $3^{\circ}$ ano do Ensino Médio. De acordo com o documento examinado, "[...] as questões que compõem o instrumento dizem respeito às atitudes, sentimentos ou percepções dos alunos em relação a si mesmos e só admitem uma resposta como mais adequada". (IAS, 2014, p. 25). Ele pode ser aplicado pelos professores como uma tarefa específica de aula com duração aproximada de 40 minutos. O Quadro 2, a seguir, apresenta um exemplo de questão.

QUADRO 2 - QUESTIONÁRIO SOCIOEMOCIONAL

\begin{tabular}{|l|c|c|c|c|c|}
\hline \multicolumn{1}{|c|}{$\begin{array}{c}\text { Avalie na escala abaixo o quanto } \\
\text { você consegue }\end{array}$} & $\begin{array}{c}1 \\
\text { Nada }\end{array}$ & $\begin{array}{c}2 \\
\text { Pouco }\end{array}$ & $\begin{array}{c}3 \\
\text { Mais ou menos }\end{array}$ & $\begin{array}{c}4 \\
\text { Muito }\end{array}$ & $\begin{array}{c}5 \\
\text { Totalmente }\end{array}$ \\
\hline $\begin{array}{l}\text { 1. Fazer perguntas para compreender melhor } \\
\text { um assunto. }\end{array}$ & & & & & \\
\hline $\begin{array}{l}\text { 2. Colaborar com algum colega quando o ob- } \\
\text { serva tendo dificuldade. }\end{array}$ & & & & & \\
\hline $\begin{array}{l}\text { 3. Apresentar disposição para atividades mais } \\
\text { longas e complexas. }\end{array}$ & & & & & \\
\hline
\end{tabular}

FONTE: IAS (2014). 
Considerando que tais estratégias interventivas são mobilizadas no âmbito de um Estado em rede, bem como pela sua intencionalidade dirigida aos investimentos econômicos e à personalização dos percursos formativos, constatamos que as racionalidades políticas orientadoras da escolarização contemporânea são deslocadas para o âmbito dos indivíduos. Esse deslocamento da racionalidade interventiva, mais do que enunciar uma predominância do neoliberalismo enquanto grade de inteligibilidade, supõe um uso econômico para a constituição subjetiva dos indivíduos. Como é possível perceber a partir da leitura das tabelas, a linguagem da expertise psicológica é utilizada como pressuposto de viabilização de comparações. Nesse sentido, pode-se dizer que se constitui um rol de palavras, de definições, de conceitos, a partir de uma linguagem específica que permite as operações de notação, inscrição e cálculo das competências socioemocionais dos alunos. (MILLER; ROSE, 2012).

\section{Considerações finais}

Ao finalizarmos nossa composição analítica, podemos afirmar que, a partir da produção de saberes estatísticos (SENRA, 2005) sobre as competências socioemocionais dos alunos, tornam-se os traços da população discente calculáveis e inteligíveis. Em decorrência desse processo, planejam-se ações com o intuito de agir sobre os aspectos levantados como problemáticos pelos cálculos estatísticos, a partir da análise dos questionários respondidos pelos alunos. Desse modo, desenvolve-se um processo de inteligibilidade sobre a população discente, para posteriormente poder operar sobre ela por meio de políticas educacionais e práticas pedagógicas, cujo foco é a potencialização das aprendizagens com base no desenvolvimento das competências nas quais os alunos apresentam menos destaque (ESPING-ANDERSEN, 2007). Em suma, potencializar o desenvolvimento das competências socioemocionais dos estudantes torna-se um imperativo de um Estado que procura extrair da população a potência produtiva e, com isso, minimizar situações que possam gerar despesas futuras ligadas às áreas da segurança, da saúde e da educação.

A partir da dinâmica apresentada, constituída pelos processos de inteligibilidade e operacionalidade (FARHI NETO, 2008), evidenciam-se as formas de atuação do Estado através de agenciamentos políticos envolvendo parcerias, organizações não governamentais e organismos internacionais, colocando em ação uma forma de "governança em rede" (BALL, 2014, p. 188), como sinalizamos anteriormente. Tal forma de governança, com maior ou menor 
intensidade, dá visibilidade para uma nova arquitetura institucional. Para além da predominância de novas formas de "economização da vida social", o que já seria representativo, as atuais formas de intervenção estatal definem seus critérios de sucesso, especialmente no que tange à escolarização pública.

Como consequência das discussões apresentadas no decorrer do artigo, é interessante compartilhar o argumento defendido por Simons e Masschlein (2008, p. 193): "[...] a educação pode ser considerada como uma indústria do conhecimento". Desse modo, é possível inferir que é a partir dessa "indústria educacional", motivada contemporaneamente pela emergência de currículos socioemocionais, habilidades do século XXI e o imperativo de investimento econômico em educação, que são planejadas refinadas tecnologias que operam no mapeamento e na tentativa de potencialização das competências socioemocionais dos alunos, tendo em vista a qualificação do capital humano.

\section{REFERENCIAS}

BALL, S. Educação Global S.A.: novas redes políticas e imaginário neoliberal. Ponta Grossa: Editora UEPG, 2014.

BRASIL. Constituição (1988). Emenda Constitucional no 59, de 11 de novembro de 2009. Diário Oficial da União, Brasília, DF, 12 nov. 2009.

BRASIL. Lei n ${ }^{\circ} 11.114$, de 16 de maio de 2005 . Altera os artigos $6^{\circ}, 30,32$ e 87 da Lei no 9.394, de 20 de dezembro de 1996, com o objetivo de tornar obrigatório o início do ensino fundamental aos seis anos de idade. Diário Oficial da União, Brasília, DF, 17 maio 2005.

BRASIL. Lei $n^{\circ}$ 12.796, de 4 de abril de 2013. Altera a Lei $n^{\circ}$ 9.394/96, de 20 de dezembro de 1996, que estabelece as diretrizes e bases da educação nacional, para dispor sobre a formação dos profissionais da educação e dar outras providências. Diário Oficial da União, Brasília, DF, 4 abr. 2013.

CORREA, B. C. Educação infantil e ensino fundamental: desafios e desencontros na implantação de uma nova política. Educação e Pesquisa, São Paulo, v. 37, n. 1, p. 105120, jan./abr. 2011.

CUNHA, F. et al. Interpreting the evidence on life cycle skill formation. NBER Working Paper Series, Cambridge, MA, n. 11331, p. 1-164, May 2005.

CUNHA, F.; HECKMAN, J. J. Interpreting the evidence on life cycle skill formation. In: HANUSHEK, E. A.; WELCH, F. (Eds.). Handbook of the economics of education. Amsterdam: North-Holland, 2006. v. 1. n. 1. p. 698-747. 
CUNHA, F.; HECKMAN, J. J. The technology of skill formation. American Economic Review, v. 97, n. 2, p. 31-47, 2007.

CUNHA, F.; HECKMAN, J. J. Capital humano. In: ARAÚJO, A. (Coord.). Aprendizagem infantil: uma abordagem da neurociência, economia e psicologia cognitiva. Rio de Janeiro: Academia Brasileira de Ciências, 2011. p. 9-34.

ESPING-ANDERSEN, G. Investing in children and their life chance. Barcelona: Universitat Pompeaus Fabra, 2007.

FARHI NETO, L. Biopolítica como tecnologia de poder. INTERthesis: Revista Internacional Interdisciplinar, v. 5, p. 47-65, jan./jul. 2008.

FOUCAULT, M. O nascimento da biopolítica. São Paulo: Martins Fontes, 2008.

FRUYT, F. de. Personalização. Entrevista publicada em 9 dez. 2014. Disponível em: $<$ http://educacaosec21.org.br/entrevista-filip-de-fruyt/>. Acesso em: jan. 2015.

FUMAGALLI, A. Bioeconomía y capitalismo cognitivo: hacia un nuevo paradigma de acumulación. Madrid: Traficantes de Sueños, 2010.

GADELHA, S. Governamentalidade neoliberal, Teoria do Capital Humano e Empreendedorismo. Educação e Realidade, v. 34, n. 2, p. 171-186, 2009.

HECKMAN, J. J. Investing in disadvantaged young children is an economically efficient policy. Forum on "Building the economic case for investing in preschool". Nova York, 10 jan. 2006.

HECKMAN, J. J. O bom de educar desde cedo. Educar para crescer, 5 abr. 2015. Entrevista concedida a Monica Weinberg. Disponível em: $<$ http://educarparacrescer.abril. com.br/politica-publica/entrevista-james-heckman-477453.shtml>. Acesso em: jul. 2015.

HECKMAN, J. J. Schools, skills and synapses. Economic Inquiry, v. 46, n. 3, p. 298324, 2008.

INSTITUTO AYRTON SENNA (IAS). Competências socioemocionais: material para discussão. Rio de Janeiro: IAS, 2014.

JESSOP, B. ¿Narrando el futuro de la Economía Nacional y el Estado Nacional? Puntos a considerar acerca del replanteo de la regulación y la re-invención de la gobernancia. Documentos y Aportes en Administración Pública y Gestión Estatal, n. 7, p. 7-44, 2006.

LÓPEZ-RUIZ, O. Os executivos das transnacionais e o novo espírito do capitalismo: capital humano e empreendedorismo como valores sociais. Rio Janeiro: Azougue Editorial, 2007.

LUPTON, D. Risk. Londres: Routledge, 1999.

MILlER, P.; ROSE, N. Governando o presente. São Paulo: Paulus, 2012.

MOSS, P. Qual o futuro da relação entre educação infantil e ensino obrigatório? Cadernos de Pesquisa, São Paulo, v. 41, p. 142-159, jan./abr. 2011. 
NASCIMENTO, M. L. B. P. As políticas públicas de educação infantil e a utilização de sistemas apostilados no cotidiano de creches e pré-escolas públicas. Revista Brasileira de Educação, Rio de Janeiro, v. 17, n. 49, p. 59-80, 2012.

NASCIMENTO, M. L. B. P. Tupi or not tupi: escolarização desde o nascimento, a quem serve? Educação não é escolarização... Principalmente quando se trata da educação da primeira infância. Leitura: Teoria \& Prática, Campinas, v. 31, n. 61, p. 153-168, nov. 2013.

O'MALLEY, P. Risk and responsibility. In: BARRY, A.; OSBORNE, T.; ROSE, N. (Ed.). Foucault and political reason: liberalism, neoliberalism and rationalities of government. Chicago: The University of Chicago Press, 1996. p. 189-207.

PENN, H. Primeira infância: a visão do Banco Mundial. Cadernos de Pesquisa, v. 115, n. 2, p. 7-24, 2002.

ROSEMBERG, F. Uma tragédia anunciada: obrigatoriedade na pré-escola. São Paulo: Fundação Carlos Chagas, 2010.

SENRA, N. de C. O saber e o poder das estatísticas: uma história das relações dos esteticistas com os estados nacionais e com as ciências. Rio de Janeiro: IBGE, 2005.

SIMONS, M.; MASSCHELEIN, J. Se nos have crer que se trata de nuestra libertad: notas sobre la ironia del dispositivo de aprendizaje. In: SMEYERS, Paul; DEPAEPE, Marc (Eds.). Educational Research: the educationalization of social problems. v. 3. Germain: Springer, 2008. p. 191-204.

TELLO, C.; MAINARDES, J. Revisitando o enfoque das epistemologias da política educacional. Práxis Educativa, v. 10, n. 1, p. 153-178, 2015.

Texto recebido em 15 de dezembro de 2015. Texto aprovado em 18 de agosto de 2016. 